\title{
Effect of Cryogenic Treatment on Microstructure and Micro Hardness of Aluminium (LM25) - SiC Metal Matrix Composite
}

\author{
G Elango*a, BK Raghunath ${ }^{\mathrm{b}}$ and K Thamizhmaran ${ }^{\mathrm{a}}$ \\ *a Department of Mechanical Engineering, VRS College of Engineering and Technology, Arasur, Tamilnadu, India \\ ${ }^{b}$ Department of Manufacturing Engineering, Anamalai University Chidambaram, Tamilnadu, India
}

Received 4 June 2013 ; accepted 16 March 2014

\begin{abstract}
The basic aim of this paper is to increase awareness amongst the researchers and to draw their attention towards the present approach to deal with the cryogenic treatment for the nonferrous metals. Cryogenic treated nonferrous metals will exhibit longer wear and more durability. During metal making process, when solidification takes place, some molecules get caught in a random pattern. The molecules do move about at subzero and deep cryogenic treatment slowly. In this experimental study, the effect of cryogenic treatment on microstructure changes and the hardness properties varies for LM25 alloy and LM25-SiC metal matrix composite at $-196^{\circ} \mathrm{C}$. It is analyzed for different durations. The execution of cryogenic treatment on both alloy and MMCs changed the distribution of $\beta$ precipitates. The XRD crystallogram reveals that the cryogenic treatment can change the diffraction peak intensity of some crystal planes in MMCs. The influences of different volume fraction of reinforcement and cryogenic process parameters on microhardness of LM25 alloy and composite were compared with alloy and composite without cryogenic treatment and the results showed that the cryogenic treatment improves the hardness of $\mathrm{LM} 25 / \mathrm{SiC}$ composites.
\end{abstract}

Keywords: MMCs, Cryogenic treatment, Microstructure, Micro hardness.

$$
\begin{aligned}
& \text { تأثير معاجات التبريد على التركيب الجهري والصلادة الدقيقة لمعدن الالمنيوم LM25 ومركبات مصفوفة } \\
& \text { معدن SiC } \\
& \text { ج إلانجو" ، جوبالوكيشنان راغوناث و ثاميزماران كالي وارتن }
\end{aligned}
$$

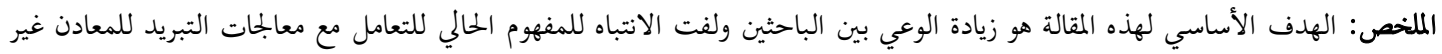

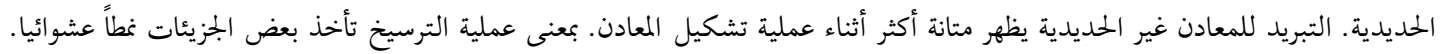

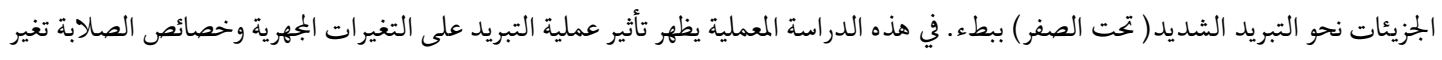

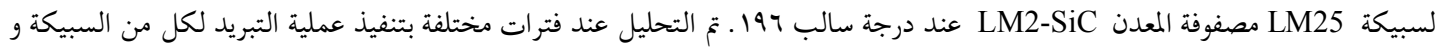

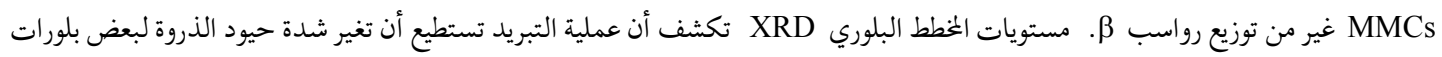

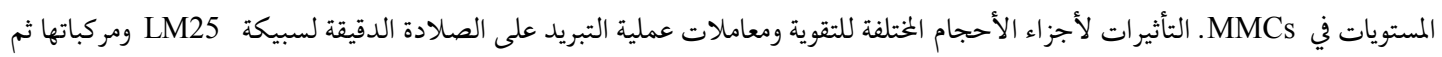

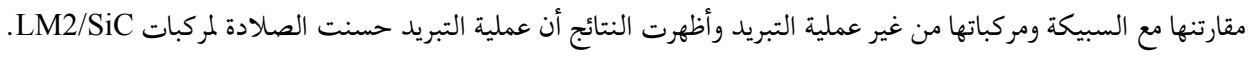

$$
\begin{aligned}
& \text { الكلمات المفتاحية: MMCs ، معالجات تبريد عميق، التركيبة الدقيقة، الصلادة الدقيقة. }
\end{aligned}
$$

$\overline{\text { *Corresponding author's e-mail: gelvan_17@yahoo.co.in }}$ 


\section{Introduction}

The attractive performance of metal matrix composites (MMCs) has been noted in a wide range of applications, from toys to high performance-requiring areas like the automobile and aerospace industries. This is due to their weight-saving characteristics and the fact that they can provide greater benefits than existing materials (Mahadevan et al. 2008). To increase the properties of these composites, several processes, like heat treatment for whole materials and surface processing are also being carried out.

On the other hand, cryogenic treatment, also known as subzero treatment, is a very old process that has been used widely for high precision parts and objects and especially for the ferrous materials mentioned earlier (Sendooran and Raja 2011). Subjecting materials properties of MMCs being developed are evaluated at cryogenic temperatures. To satisfy this requirement, in this experimental work cryogenic treatment was applied to strontium modified $\mathrm{Al}-7 \% \mathrm{Si} /$ silicon carbide (LM25/SiC) MMCs to study its effect on its microstructure and hardness.

\section{Experimentation}

The metal matrix composite was prepared by the stir casting method by taking matrix material as LM25 alloy and the particulate reinforcement as $\mathrm{SiC}$ up to a volume fraction of $20 \%$. The chemical composition of the LM25 alloy is given in Table 1. The reinforcement particles were commercial $\mathrm{SiC}$ with $99.5 \%$ purity.

Table 1. Chemical composition (\%) of LM25 aluminium alloy.

\begin{tabular}{llllllllll}
\hline $\mathbf{C u}$ & $\mathbf{S i}$ & $\mathbf{M g}$ & $\mathrm{Mn}$ & $\mathbf{F e}$ & $\mathrm{Ti}$ & $\mathrm{Ni}$ & $\mathrm{Zn}$ & $\mathrm{Sn}$ & $\mathrm{Al}$ \\
\hline 0.17 & 6.81 & 0.51 & 0.03 & 0.29 & 0.103 & 0.006 & 0.06 & $<0.001$ & balance \\
\hline
\end{tabular}

to extreme cold hardens and strengthens; this method has been used for centuries (Bensely et al. 2007). Now cryogenic treatment is widely used in the automotive, aerospace, electronic and mechanical engineering industries to improve mechanical strength and the dimensional stability of various components (Zhirafar et al. 2007). For the past few years, in order to improve properties, a cryogenic treatment for nonferrous metals such as aluminium and magnesium alloys has been used (Kaveh et al. 2009).

The mechanical properties and microstructure of metals and alloys in cryogenic treatment have drawn the attention of researchers. Lulay et al. (2002) and Jiang et al. (2009) showed the beneficial effects of cryogenic treatment on nonferrous metal aluminium. When considering the wear performance of copper alloy, cryogenic treatment yields the least significant changes (Guozhi et al. 2010). However, Woodcraft and Adam (2005) showed a significant improvement in the mechanical properties of the strength, hardness, and toughness of aluminium alloy when subjected to cryogenic treatment. This has led to the idea of analyzing individual alloys' properties when MMCs undergo cryogenic treatment.

This field is rapidly growing and is being used by many manufacturers. The present work intends to construct a facility to research the process and results of cryogenic treatment in order to create standards for both processing and testing, which are currently unavailable; hence it is important that mechanical
SiC sized 30-50 $\mu \mathrm{m}$ were used as particle reinforcement in the composite material. The reinforcement particle varied in volume fraction by $5-20 \%$ in order to manufacture different composites. The reinforcement particle was preheated to a temperature of $550^{\circ} \mathrm{C}$ to remove moisture before adding it into the molten aluminium.

To fabricate the composite, the various volume fraction of reinforced $\mathrm{SiC}$ composite material was created through the liquid metallurgy technique. In this technique, the preheated $\mathrm{SiC}$ particle was introduced into the molten pool in the vortex created in the melt by the use of a power operated stirrer, which had been coated with alumina to prevent the migration of ferrous ions from the stirrer material to the molten metal. The stirrer's speed was maintained at 550 rotations per minute (rpm) at two-thirds the depth of the molten metal. The resulting mixture of LM25 alloy and $\mathrm{SiC}$ was tilt poured into the preheated permanent mould (Elango et al. 2013).

The cryogenic treatment of samples was performed by placing a LM 25 alloy and LM $25 / \mathrm{SiC}$ specimen in a cryogenic chamber. This chamber was progressively immersed in a liquid nitrogen reservoir. The sample temperature was monitored by a K-type thermocouple which was used to operate a stepper motor which lowered the sample and maintained a temperature decline at the rate of $1^{\circ} \mathrm{C} / \mathrm{min}$. The temperature was lowered to $-196^{\circ} \mathrm{C}$ over nearly 4 hours.

The cryogenic processing method we followed, as outlined by (Kaveh et al. 2009), is a painstakingly slow, microprocessor-controlled process (Fig. 1) 
which eliminates the probability of thermal shock and micro-cracking. Specimens were held at $-196^{\circ} \mathrm{C}$ for various durations (eg. 1, 5, 10, 20, 30, 40, and 50 hours) and then slowly brought up to approximately $+25^{\circ} \mathrm{C}$.

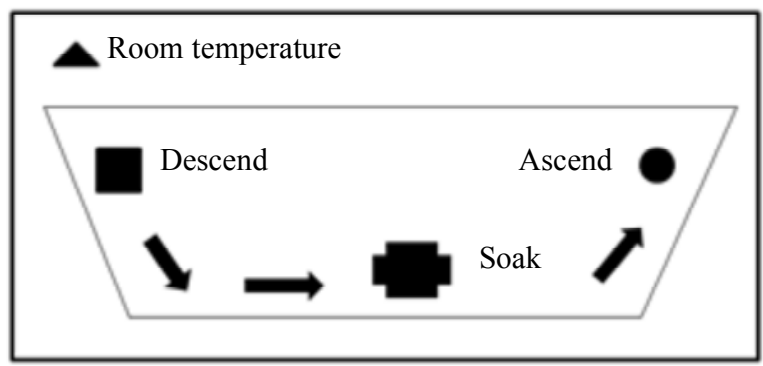

Figure 1. Cryogenic processing.

After the completion of the cryogenic processing, the specimen was prepared for microstructure analysis according to the American Society for Testing and Materials (ASTM) E3 standards. The samples were subjected to grinding and polishing followed by etching by nital. Optical microscopy was taken using a metallurgical microscope and then the specimen was washed with acetone and dried thoroughly for the hardness test. The micro hardness test was conducted using a Leitz micro hardness tester (Leica Microsystems, Wetzler, Germany) equipped with a Vickers diamond pyramid indenter. The load applied was 1 Newton.

\section{Results and Discussion}

Figures 2 and 3 show the microstructure images of the LM25 alloy and its composite before and after cryogenic processing with a $10 \%$ volume fraction of $\mathrm{SiC}$. The cryogenic processing resulted in significant changes in the microstructure of MMCs and led to the transformation of $\alpha-\mathrm{Al}$ to the $\beta\left(\mathrm{Mg}_{17} \mathrm{Al}_{12}\right)$ phase. In the LM25 alloy, the $\beta$ phase, whose main strengthening effect on A-Mg-based alloys at room temperature was proved by Mehta et al. (2004), exhibited irregular

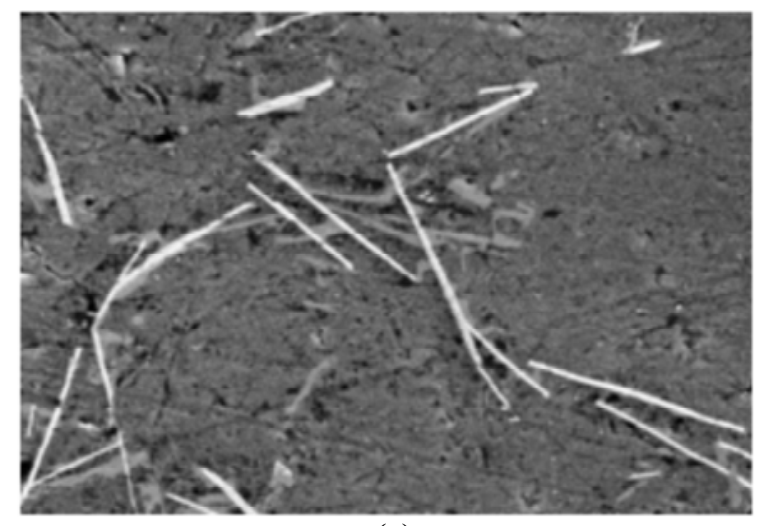

(a)

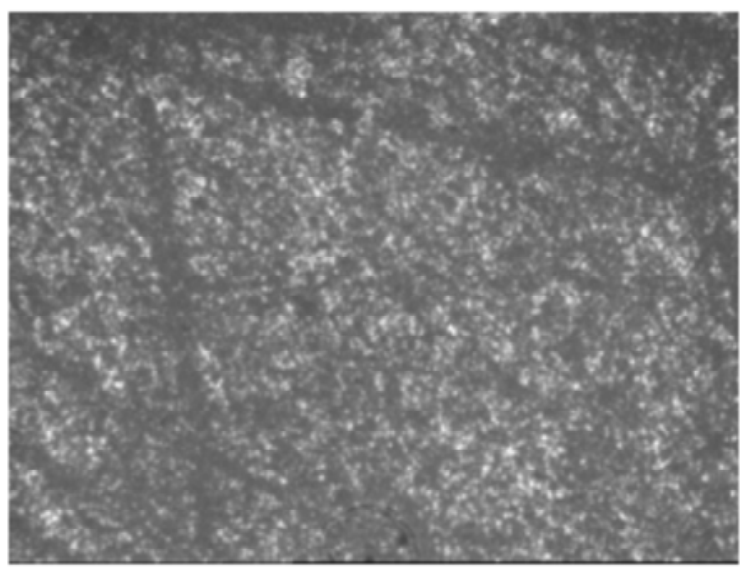

(b)

Figure 2. Microstructure of (a) LM25 alloy and (b) LM25+SiC MMCs before cryogenic treatment.

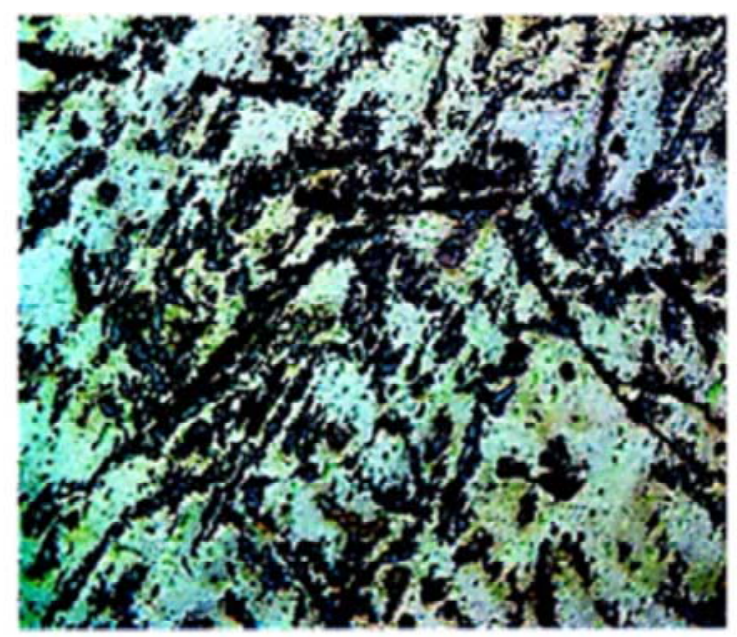

(a)

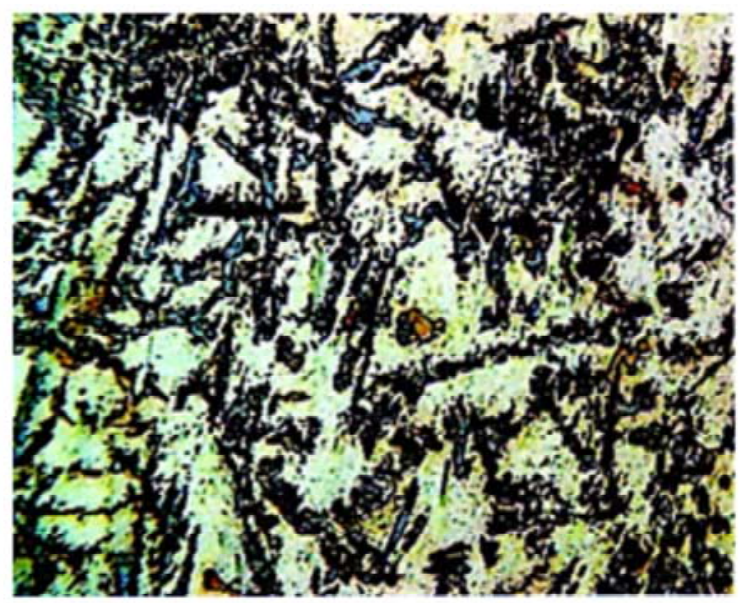

(b)

Figure 3. Microstructure of (a) LM25 alloy and (b) LM25+SiC MMCs after cryogenic treatment.

morphologies (eutectic $\beta$ phase) and tiny laminar shaped morphologies. The lower mechanical proper- 
ties at elevated temperatures is due to the low melting point of these alloys (Kaveh et al. 2009).

The cryogenic treatment of the MMCs of $\mathrm{LM} 25+\mathrm{SiC}$ led to the changes in microstructure as shown in Fig. 3(b) whereby it can be seen that the coarse divorced $\beta$ phase penetrated the matrix alloy. This improvement in hardness was the strengthening of the matrix against propagation of the existing defect, which is due to the important role of $\beta$ precipitates in the microstructure. These provide the main strengthening effect at room temperature.

The XRD pattern before and after cryogenic treatment was studied. It reveals that cryogenic treatment can change the diffraction peak intensity of the crystal planes in these alloys. Figure 4(a) shows the XRD pattern of LM25+SiC MMCs before cryogenic treatment has a range of incident angle between $30-100^{\circ}$. The target is $\mathrm{Cu} \mathrm{Ka}$, the tube voltage is $40 \mathrm{KV}$ and the electric current is $60 \mathrm{~mA}$. The properties of MMCs are related to its XRD patterns gained from the surface of MMCs.

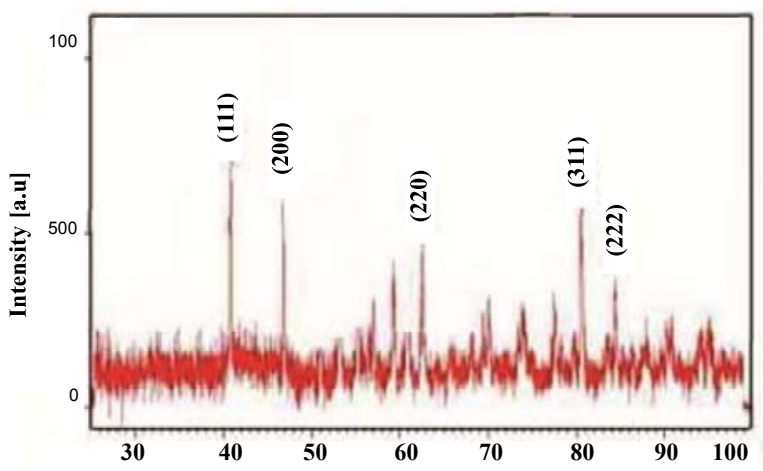

(a)

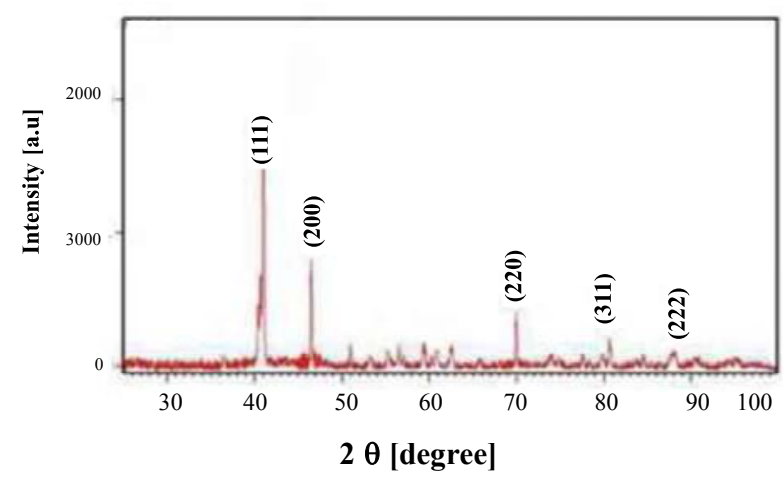

(b)

Figure 4(a) \& (b). XRD patterns of $\mathrm{LM} 25+\mathrm{SiC}$ MMCs before and after cryogenic treatment.

Figure 4(b) shows that virgin surfaces of Al MMCs are mainly consistent with the standard pattern for FCC Al. In the XRD pattern after cryogenic treatment, all the peaks are consistent except for the half width of the (111) peak decrease. This indicates that the grains in MMCs become larger after cryogenic treatment. Govindan et al. (2000) showed that the crystallization strengthens after the specimens have been cryogenic treated. Due to this change in microstructure, the hardness of the cryogenic-treated samples was increased as compared with the cast specimen with no treatment as shown in Figs. 5 and 6.

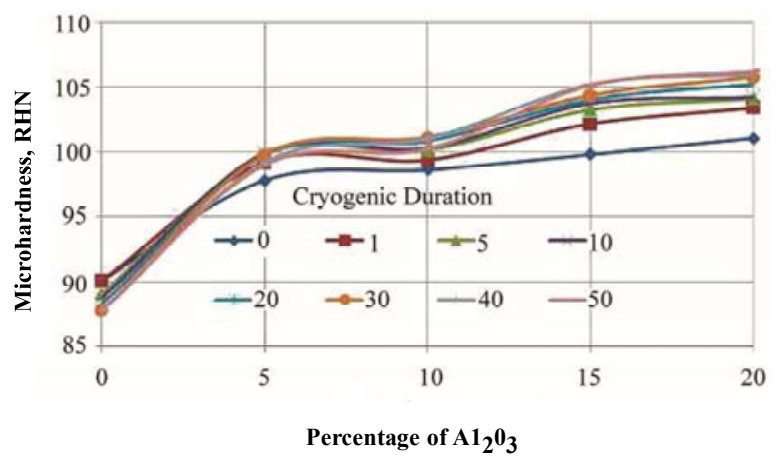

Figure 5. Effect of reinforcement on hardness of the LM25+SiC MMCs.

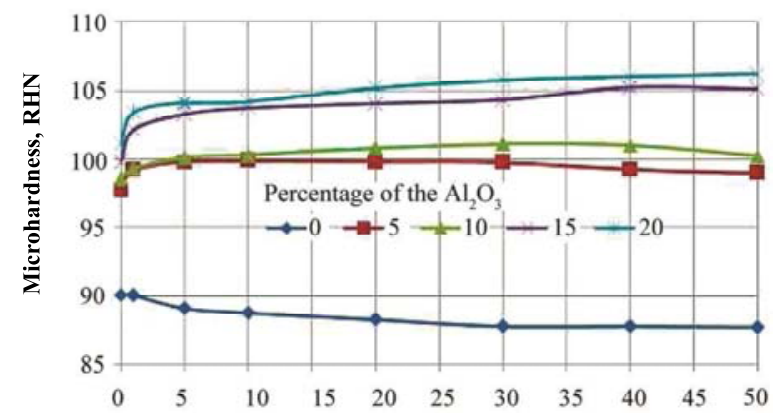

Cyrogenic treatment duration in hours

Figure 6. Effect of cryogenic treatment duration on microhardness of LM25 alloy and LM25+ SiC MMCs.

Figure 5 shows the percentage of reinforcement and cryogenic duration on the hardness properties of MMCs. It clearly depicts the increase in hardness for the increase in reinforcement percentage and the cryogenic duration in hours.

The results show that hardness decreases in the LM25 alloy with increasing cryogenic treatment. This improvement was attributed to the strengthening of the matrix against the propagation of the existing defects, which is due to the important role of $\beta$ precipitates in the microstructure. The $\beta$ precipitates contribute the main strengthening effect at room temperature. Since the $\beta$ precipitates are mainly distributed at the grain boundaries, the morphology of the $\beta$ particles after cryogenic treatment helps in stabilization of internal microstructure. In LM25, alloys discontinue precipi- 
tation of $\beta$-dominance at grain boundaries, weaken the grain boundaries and reduce the hardness with increasing cryogenic duration. The XRD observation showed the cryogenic treatment caused the grain boundaries to break, resulting in many grains sized $1-3 \mu \mathrm{m}$. The broken eq-uiaxial grains MMCs improve the hardness of the matrix alloy.

\section{Conclusions}

In conclusion, cryogenic treatment changes the morphology of precipitates in both the LM25 alloy and LM25+SiC composite. The hardness of the cryogenic-treated MMCs samples can improve due to the coarse eutectic $\beta$ phase present in the matrix as compared with cast samples. The hardness increases with the increasing volume percentage of reinforcement for the MMCs for the same cryogenic condition. The application of cryogenic treatment has increased the effects of particulates with an increase in particulate percentage but pure Al decreased the effect of cryogenic treatment. Micro structural changes occurred during initial cryogenic treatment which is felt in the changes in the diffraction pattern in XRD.

\section{References}

Bensely A, Senthilkumar D, Mohan LD, Nagarajan G, Rajadurai A (2007), Effect of cryogenic treatment on tensile behavior of case carburized steel815M1. Materials Characterization 58(5):485491.

Elango G, Raghunath BK, Palanikumar K (2013), Sliding wear of LM25 aluminium alloy with 7.5\% $\mathrm{SiC}+2.5 \% \mathrm{~T}_{\mathrm{i}} \mathrm{O}_{2}$ and $2.5 \% \mathrm{SiC}+7.5 \% \mathrm{~T}_{\mathrm{i}} \mathrm{O}_{2}$ and $2.5 \% \mathrm{SiC}+7.5 \% \mathrm{~T}_{\mathrm{i}} \mathrm{O}_{2}$ hybrid composites. DOI: 10.1177/0021998313496592 1-10.

Govindan PPK, Nageswara RB, Srivastava VK (2000), Residual strength of aluminum-lithium alloy center surface crack tension specimens at cryogenic temperatures. Cryogenics 40:789-795.

Guozhi Ma, Ding C, Zhenhua C, Wei Li (2010), Effect of cryogenic treatment on microstructure and mechanical behaviors of the $\mathrm{Cu}$-based bulk metallic glass matrix composite. Journal of Alloys and Compounds 505(1):319-323.

Jiang XQ, Ning Li, Hong He, Zhang XJ, Hao Y (2009), Effect of cryogenic treatment on mechanical properties and microstructure of $3102 \mathrm{Al}$ alloy. Materials Science Forum 546-49(2):845848.

Kaveh MA, Alireza T, Farzad K (2009), Effect of deep cryogenic treatment on microstructure, creep and wear behaviors of AZ91 magnesium alloy. Materials Science and Engineering A 523:27-31.

Khomamizadeh F (2009), Effect of deep cryogenic treatment on microstructure, creep and wear behaviors of AZ91 magnesium alloy. Materials Science and Engineering A 523:27-31.

Lulay KE, Khan K, Chaaya D (2002), The Effect of Cryogenic Treatments on 7075 Aluminum alloy. Journal of Materials Engineering and Performance 11(5):479-480.

Mahadevana K, Raghukandanb K, Pai UTS, Pillai BC (2008), Influence of precipitation hardening parameters on the fatigue strength of AA 6061SiCp composite. Journal of Materials Processing Technology 198:241-247.

Mehta DS, Masood SH, Song WQ (2004), Investigation of wear properties of magnesium and aluminum alloys for automotive applications. Journal of Materials Processing Technology 155156:1526-1531.

Sendooran S, Raja P (2011), Metallurgical investigation on cryogenic treated HSS tool. International Journal of Engineering Science and Technology 3(5):3992-3996.

Woodcraft, Adam L (2005), Recommended values for the thermal conductivity of aluminium of different purities in the cryogenic to room temperature range and a comparison with copper. Cryogenics 45(9):626-636.

Zhirafar S, Rezaeian A, Pugh M (2007), Effect of cryogenic treatment on the mechanical properties of 4340 steel. Journal of Materials Processing Technology 186(1-3):298-303. 